\title{
Enhanced antitumor effect of cytotoxic T lymphocytes induced by dendritic cells pulsed with colorectal cancer cell lysate expressing $\alpha$-Gal epitopes
}

\author{
XIAOWEI XING ${ }^{1 *}$, ZHENYU ZOU ${ }^{2 *}$, CHANGZHENG HE $^{1}$, ZILONG HU ${ }^{1}$, \\ KAI LIANG ${ }^{1}$, WENTAO LIANG ${ }^{1}$, YUFENG WANG ${ }^{3}$ and XIAOHUI DU ${ }^{1}$ \\ ${ }^{1}$ Department of General Surgery, Chinese People's Liberation Army General Hospital; \\ ${ }^{2}$ Department of Hernia and Abdominal Wall Surgery, Beijing Chao-Yang Hospital, Capital Medical University; \\ ${ }^{3}$ Department of Patient Admission Management, Chinese People's Liberation Army General Hospital, \\ Beijing 100853, P.R. China
}

Received June 1, 2018; Accepted April 24, 2019

DOI: $10.3892 / \mathrm{ol} .2019 .10376$

\begin{abstract}
Colorectal cancer (CRC) is one of the most common types of gastrointestinal malignancy. Traditional therapeutic options for CRC exhibit a limited effect. Adoptive cellular therapy has emerged as a new treatment strategy for CRC. Dendritic cells (DCs) are potent antigen-presenting cells. Specific cytotoxic T lymphocytes (CTLs) activated by DCs pulsed with tumor lysate have been reported to be a safe and promising treatment approach for CRC. However, the antitumor effect of specific CTLs remains limited. The low immunogenicity of tumor-associated antigens (TAAs) is the main reason for this limited therapeutic effect. In the present study, $\alpha$-gal epitopes were synthesized on the CRC cell line SW620 to increase the immunogenicity of TAAs. DCs were pulsed with $\alpha$-gal-expressing tumor lysate and CTLs were activated by these DCs. The cytotoxicity of CTLs was measured in vitro. The results demonstrated that DCs pulsed with $\alpha$-gal-expressing tumor lysate can increase the frequency of $\mathrm{CD}^{+}{ }^{+} \mathrm{CD}{ }^{+} \mathrm{CTL}$ and natural killer $\mathrm{T}$ cells, increase the level of tumor necrosis factor- $\alpha$ produced by CTLs and enhance the cytotoxicity of CTLs against tumor cells. Therefore, this novel
\end{abstract}

Correspondence to: Professor Xiaohui Du, Department of General Surgery, Chinese People's Liberation Army General Hospital, 28 Fuxing Road, Haidian, Beijing 100853, P.R. China

E-mail: duxiaohui301@sina.com

${ }^{*}$ Contributed equally

Abbreviations: CRC, colorectal cancer; ACT, adoptive cellular therapy; DC, dendritic cell; CTL, cytotoxic T lymphocyte; TAA, tumor-associated antigen; NKT, natural killer T cell; Treg, regulatory $\mathrm{T}$ cell; HLA, human leukocyte antigen; TNF, tumor necrosis factor; IL, interleukin

Key words: CRC, DC, cytotoxic $\mathrm{T}$ cell, $\alpha$-gal epitopes, immunogenicity, TAA approach may be an effective treatment strategy for patients with CRC.

\section{Introduction}

Colorectal cancer (CRC) is one of the most common types of gastrointestinal malignancy and is the fourth leading cause of cancer-associated mortality worldwide (1). The therapeutic effects of traditional treatment options, including surgery and adjuvant chemotherapy, are limited and the majority of patients develop drug resistance and disease recurrence $(2,3)$. Therefore, there is an urgent requirement to develop novel treatment strategies for CRC. Adoptive cellular immunotherapy (ACT) has the potential to fulfill this requirement. The success of ACTs for hematological malignancies has increased the interest for investigating ACT for the treatment of solid tumors, including CRC $(4,5)$.

Useful approaches of ACT for the treatment of CRC include the use of dendritic cell (DC) pulsed with tumor-associated antigens (TAAs) and cytotoxic T lymphocytes (CTLs) activated using those DCs (6-9). However, these treatment strategies are unable to generate sufficient antitumor immune responses. One possible reason for this is the low immunogenicity of TAAs, which results in inadequate activity of the host immune system and treatment failure (10). DCs are the most potent types of antigen-presenting cells and are critical for the activation of the immune response (11). DCs are capable of presenting tumor antigen to naïve $\mathrm{T}$ cells in a human leukocyte antigen (HLA)-restricted manner. However, the low immunogenicity of TAAs may result in inadequate stimulation of DCs and defective DCs cannot effectively induce CTLs against tumors. One possible approach to increase the presentation of TAAs by DCs is to synthesize $\alpha$-gal epitopes on tumor cells $(12,13)$.

The $\alpha$-gal epitope is abundantly presented in non-primate mammals and New World monkeys, but it is absent in humans, apes and Old World monkeys (14). However, natural anti-gal antibody has been identified to be present in human serum in large amounts and is responsible for the hyperacute rejection 
of xenotransplantation (15). Once anti-gal binds to the $\alpha$-gal epitope, the Fc portion of anti-gal binds to Fc $\gamma$ receptor III on DCs (16). This interaction can induce effective phagocytosis of DCs and increase the presentation of TAAs (17). The $\alpha$-gal epitope is synthesized by the enzyme $\alpha 1,3$ Galantosyltransferase $(\alpha 1,3 \mathrm{GT})$, which is present within the Golgi of cells. Galactose is transferred by $\alpha 1,3 \mathrm{GT}$ from the sugar-donor uridine diphosphate-gal to the acceptor $\mathrm{N}$-acetyllactosamine residue (Gal $\alpha 1-4 G l c N A c-R)$ to synthesize the $\alpha$-gal epitope (18). The expression of $\alpha$-gal epitopes on tumor cells can be successfully achieved by the transduction of a recombinant lentivirus vector expressing the $\alpha 1,3 \mathrm{GT}$ gene (19).

The present study presents a new therapeutic strategy for $\mathrm{CRC}$, in which $\alpha$-gal epitopes were successfully synthesized on the CRC SW620 cell line and tumor lysate expressing $\alpha$-gal epitopes was used to maximize DC phagocytosis and activate CTLs to kill CRC cells in vitro.

\section{Materials and methods}

Cell culture. The human CRC cell line SW620 and 293T cells were purchased from American Tissue Culture Collection (Manassas, VA, USA). These cell lines were cultured in Dulbecco's modified Eagle's medium (Gibco; Thermo Fisher Scientific, Inc., Waltham, MA, USA) supplemented with $10 \%$ heat-inactivated fetal bovine serum (Gibco; Thermo Fisher Scientific, Inc., Waltham, MA, USA), $50 \mathrm{U} / \mathrm{ml}$ penicillin, $50 \mathrm{mg} / \mathrm{ml}$ streptomycin and $4 \mathrm{mM}$ glutamine in a humidified incubator with $5 \% \mathrm{CO}_{2}$ at $37^{\circ} \mathrm{C}$.

Construction of a recombinant lentivirus vector expressing murine $\alpha 1,3 G T$ gene. Untransfected cells were termed SW620-normal, SW620 cells transfected with an empty vector were termed SW620-control and cells transfected with the recombinant lentivirus vector expressing the $\alpha 1,3 \mathrm{GT}$ gene were termed SW620- $\alpha$-gal. The coding sequence (CDS) of the $\alpha 1,3 \mathrm{GT}$ gene was identified from GenBank (www.ncbi.nlm. nih.gov/nuccore/NM_001145821.2) and primers for amplification of the CDS of the $\alpha 1,3 \mathrm{GT}$ gene were designed using Vector NTI (version 10.3; Invitrogen; Thermo Fisher Scientific, Inc.). pLenti-CMV-mCherry-3FLAG-PGK-Puro was digested by $\mathrm{BamHI}-\mathrm{HF}$ and the $\alpha 1,3 \mathrm{GT}$ gene was subcloned into pLen ti-CMV-mCherry-3FLAG-PGK-Puro (Shanghai Heyuan, Shanghai, China) to construct pLenti-CMV-mCherry-2A- $\alpha 1$ ,3GT-3FLAG-PGK-Puro. This recombinant lentivirus vector was transfected at a concentration of $800 \mathrm{ng} / \mu 1$ into packaging 293T cells using HitransG P transfection reagent (Shanghai GeneChem). High titers of recombinant lentivirus vector were amplified, purified and stored. Finally, SW620 cells were transfected with the recombinant lentivirus vector expressing the $\alpha 1,3 \mathrm{GT}$ gene at a multiplicity of infection of $200 \mathrm{using}$ HitransG P tranfection reagent (Genechem, shanghai, China), which generated SW620- $\alpha$-gal epitopes. An empty vector (pLenti-CMV-mCherry-3FLAG-PGK-Puro) was used for transfection of the control group. The subsequent experiments were performed $72 \mathrm{~h}$ after transfection.

Reverse transcription-quantitative polymerase chain reaction $(R T-q P C R)$. Total RNA was extracted from the SW620-normal, SW620-control and SW620- $\alpha$-gal cells using
TRIzol $^{\circledR}$ (Invitrogen; Thermo Fisher Scientific, Inc.). cDNA was synthesized using RevertAid First Strand cDNA Synthesis kit (Thermo Fisher Scientific, Inc.) at $42{ }^{\circ} \mathrm{C}$ for $60 \mathrm{~min}$ and $70^{\circ} \mathrm{C}$ for $5 \mathrm{~min}$, according to the manufacturer's protocol. RT-qPCR was carried out using Applied Biosystems ${ }^{\circledR}$ ViiA $^{\mathrm{TM}}$ 7 system, and subsequently amplified using SYBRGreen PCR Master mix (Beyotime Institute of Biotechnology) and $0.5 \mu \mathrm{M}$ each of the sense and antisense primers. PCR amplification was performed with an initial denaturation at $95^{\circ} \mathrm{C}$ for $5 \mathrm{~min}$, followed by 40 cycles of $30 \mathrm{sec}$ at $95^{\circ} \mathrm{C}, 30 \mathrm{sec}$ at $60^{\circ} \mathrm{C}$ and $30 \mathrm{sec}$ at $72^{\circ} \mathrm{C}$. $\beta$-actin was chosen as the reference gene with the following primer pairs: Forward, 5'-CATGTACGT TGCTATCCAGGC-3' and reverse, 5'-CTCCTTAATGTC ACGCACGAT-3'. The primers for $\alpha 1,3 \mathrm{GT}$ were as follows: Forward, 5'-TCTGAGAAGAGGTGGCAGGA-3' and reverse, 5'-GGTGAACTTCTCGGGACTGG-3'. Relative gene expression data was analyzed by the $2^{-\Delta \Delta \mathrm{Cq}}$ method (20).

DC and CTL preparation. The present study was approved by the Ethics Committee of Chinese People's Liberation Army General Hospital (Beijing, China). Written informed consent was obtained from all volunteers (two males; 28 and 31 years old, respectively) and blood collection took place in October 2017. DCs and CTL were prepared as previously described (21). Briefly, peripheral blood mononuclear cells (PBMCs) were obtained from the peripheral blood of the healthy volunteers $(20 \mathrm{ml})$ using density gradient centrifugation $(1,500 \mathrm{x} \mathrm{g}$ for $20 \mathrm{~min}$ at $\left.37^{\circ} \mathrm{C}\right)$. PBMCs were cultured in serum-free Cellix 901 medium (Xinminglitai, Beijing, China) for $3 \mathrm{~h}$. The adherent cells were cultured in Cellix 901 medium containing granulocyte-macrophage colony-stimulating factor $(1,000 \mathrm{U} / \mathrm{ml})$ and recombinant human interleukin-4 $(1,000 \mathrm{U} / \mathrm{ml})$. On day 8 , the DCs were co-cultured with SW620-normal, SW620-control and SW620- $\alpha$-gal cell lysates in Cellix 901 and 10\% human AB group serum (Gibco; Thermo Fisher Scientific, Inc.) overnight in an incubator with $5 \% \mathrm{CO}_{2}$ at $37^{\circ} \mathrm{C}$. On day 9 , the DCs were harvested, washed and resuspended. The harvested DCs were co-cultivated with non-adherent PBMCs separated from the second collection of the same volunteer's blood for 14 days to harvest CTLs. The CTLs activated by DCs cultured with SW620-normal, SW620-control and SW620- $\alpha$-gal cell lysates were referred to as CTL-normal, CTL-control and CTL- $\alpha$-gal, respectively.

Flow cytometric analysis. The expression of $\alpha$-gal epitopes on SW620- $\alpha$-gal cells was evaluated by flow cytometry. Firstly, $\sim 1 \times 10^{6} \alpha-1,3 \mathrm{GT}$-transfected cells were suspended in PBS and incubated with fluorescein isothiocyanate (FITC)-BS-IB4 lectins (Sigma-Aldrich; Merck KGaA), which specifically bind to $\alpha$-gal epitopes. Phenotypic analysis was performed by flow cytometry. The following antibodies were used: Anti-CD80 (cat. no. 557227; 1:40), anti-CD8 (cat. no. 557086; 1:20) and anti-CD127 conjugated with phycoerythrin (cat. no. 561028; 1:20); anti-CD83 (cat no. 551073, 1:40), anti-CD56 (cat. no. $565139 ; 1: 20)$ and anti-CD25 conjugated with allophycocyanin (cat. no. 560987; 1:20); anti-CD86 (cat no. 557343, 1:40) and anti-CD4 conjugated with FITC (cat no. 555346, 1:20); and anti-HLA-DR (cat no. 552764, 1:40) and anti-CD3 conjugated with peridinin chlorophyll protein complex (cat no. 552851, 1:20). All the antibodies were purchased from 
BD Biosciences. CTL cells were evaluated using anti-CD3, anti-CD4, anti-CD8, anti-CD56, anti-CD25 and anti-CD127. DC maturation was evaluated using anti-CD80, anti-CD83, anti-CD86 and anti-HLA-DR. Briefly, $\sim 1 \times 10^{5}$ cells were stained with the appropriate antibodies in FACS buffer for $30 \mathrm{~min}$ at $4^{\circ} \mathrm{C}$ in the dark. All analyses were performed with a FACS Calibur flow cytometer (BD Biosciences, San Jose, CA, USA) and CellQuest software (version 1.0; BD Biosciences).

ELISA. The detection of IL-10 and IL-12 secreted by DCs, and IL- 4 and tumor necrosis factor- $\alpha$ (TNF- $\alpha$ ) secreted by CTL cells was performed using appropriate ELISA kits (R\&D Systems, Inc., Minneapolis, MN, USA), according to the manufacturer's protocol. The following kits were used: Human IL-10 quantikine ELISA kit (cat. no. S1000B), human IL-12 p70 quantikine ELISA kit (cat. no. S1200), human IL-4 quantikine ELISA kit (cat. no. S4050) and human TNF- $\alpha$ quantikine ELISA kit (cat. no. STA00D).

Cytolytic assay. The cytotoxicity of CTL-normal, CTL-control and CTL- $\alpha$-gal cells induced by different antigen-pulsed DCs against normal SW620, SW620-control and SW620- $\alpha$-gal cells was evaluated using a lactate dehydrogenase release assay (CytoTox $96^{\circledR}$ Non-Radioactive Cytotoxicity assay; Promega Corporation, Madison, WI, USA), according to the manufacturer's protocol.

Statistical analysis. All experiments were repeated three times. Data are presented as the mean \pm standard deviation. Statistical analyses were performed with SPSS 17.0 (SPSS, Inc., Chicago, IL, USA). Differences among groups were compared with one-way analysis of variance followed by a Fisher's Least Significance Difference post hoc test. $\mathrm{P}<0.05$ was considered to indicate a statistically significant difference.

\section{Results}

Generation of a stable SW620 CRC cell line expressing $\alpha$-gal epitopes. A recombinant lentivirus vector expressing the murine $\alpha 1,3 \mathrm{GT}$ gene was constructed and transferred into SW620 cells to produce SW620- $\alpha$-gal cells. A total of $72 \mathrm{~h}$ after lentivirus infection, overexpression of $\alpha 1,3 \mathrm{GT}$ mRNA in SW620 cells was determined by RT-qPCR. As presented in Fig. 1, the expression of $\alpha 1,3 \mathrm{GT}$ mRNA in SW620- $\alpha$-gal cells was significantly higher compared with that observed in SW620-normal and SW620-control cells $(\mathrm{P}<0.01)$. The flow cytometry assay demonstrated that $>88 \%$ of SW620-transfected cells expressed $\alpha$-gal epitopes on the surface (Fig. 2).

Effect of pulsing with a-gal expressing tumor lysate on DC maturation and cytokine production. Changes in DC immunophenotype and cytokine production were detected by flow cytometry and ELISA to evaluate the effects of $\alpha$-gal expressing tumor lysate on DC maturation. DCs treated with SW620-normal cell lysate, SW620-control cell lysate and SW620- $\alpha$-gal cell lysate were referred to as DC-normal, DC-control and DC- $\alpha$-gal, respectively. The co-stimulatory molecules CD80 and CD86, and the maturation markers CD83 and HLA-DR were evaluated. As presented in Fig. 3, the SW620 cell lysate- and SW620-control cell lysate-treated DCs
Table I. CTLs activated by dendritic cells pulsed with $\alpha$-gal expressing tumor lysate elicited significant cytotoxic responses against SW620 and SW620- $\alpha$-gal cells as determined by the cytolytic assay.

\begin{tabular}{lccl}
\hline SW620 cell & CTL-normal & CTL-control & CTL- $\alpha$-gal \\
\hline SW620-normal & $46.1 \pm 3.52$ & $48.4 \pm 4.00$ & $57.2 \pm 5.27^{\mathrm{a}, \mathrm{b}}$ \\
SW620-control & $44.6 \pm 2.81$ & $49.6 \pm 1.56^{\mathrm{a}}$ & $42.6 \pm 1.75^{\mathrm{b}}$ \\
SW620- $\alpha$-gal & $46.7 \pm 2.33$ & $46.8 \pm 2.17$ & $64.8 \pm 2.74^{\mathrm{a}, \mathrm{b}}$ \\
\hline
\end{tabular}

${ }^{\mathrm{a}} \mathrm{P}<0.05$ vs. CTL-normal, ${ }^{\mathrm{b}} \mathrm{P}<0.05$ vs. CTL-control. CTL, cytotoxic T lymphocyte.

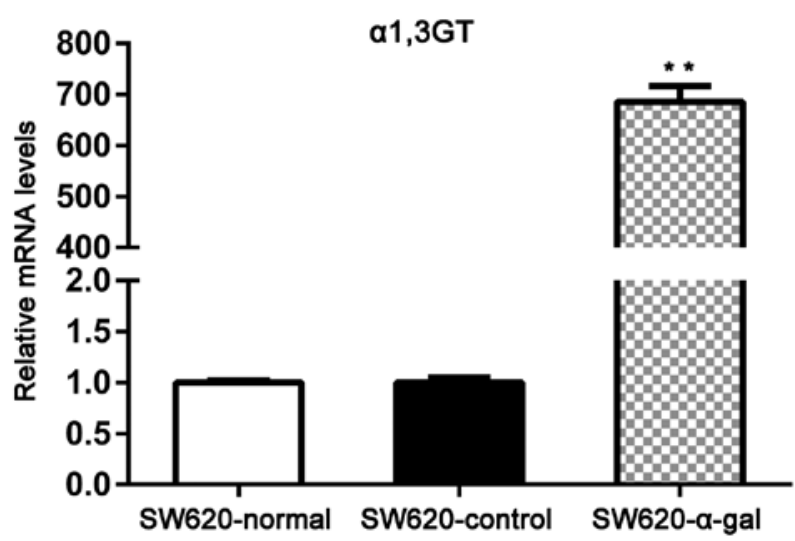

Figure 1. Overexpression of $\alpha 1,3 \mathrm{GT}$ mRNA in SW620 cells was determined by reverse transcription-quantitative polymerase chain reaction. The expression of $\alpha 1,3 \mathrm{GT}$ mRNA significantly increased in SW620- $\alpha$-gal cells compared with SW620-normal cells. ${ }^{* *} \mathrm{P}<0.01 . \alpha 1,3 \mathrm{GT}, \alpha 1,3 \mathrm{Galantosyltransferase}$.

exhibited significantly lower expression levels of CD80 and HLA-DR, and significantly higher expression levels of CD83 compared with SW620- $\alpha$-gal cell lysate-treated DCs. No significant difference in the expression of CD86 was identified between the DCs treated with the different cell lysates.

The secretion of inflammatory cytokines is another important function of DCs. Therefore, the secretion of IL-10 and IL-12 from DCs was detected using ELISA. The level of IL-12 secreted by DC- $\alpha$-gal was significantly higher compared with that secreted by DC-control and higher than that secreted by DC-normal, although no statistical difference was revealed. The level of IL-10 secreted by DC- $\alpha$-gal was significantly lower compared with that secreted by DC-control and DC-normal (Fig. 4). These results demonstrate that pulsing with $\alpha$-gal expressing SW620 cell lysate may enhance the Th1-type cytokine secretion and impair the Th2-type cytokine secretion of DCs.

Subgroup and cytokine production analysis of $T$ cells. T cell subgroups and cytokine production were also detected by flow cytometry and ELISA. The frequencies of T helper cells $\left(\mathrm{CD}^{+} \mathrm{CD}^{+}\right)$, CTLs $\left(\mathrm{CD}^{+}{ }^{+} \mathrm{CD} 8^{+}\right)$, NKT cells $\left(\mathrm{CD}^{+}{ }^{+} \mathrm{CD} 56^{+}\right)$ and regulatory $\mathrm{T}$ cells $\left(\right.$ Tregs; $\mathrm{CD} 3^{+} \mathrm{CD} 4^{+} \mathrm{CD} 25^{\text {hi }} \mathrm{CD} 127^{\text {lo }}$ ) were evaluated. As presented in Fig. 5, the frequency of $\mathrm{CD}^{+}{ }^{+} \mathrm{CD} 8^{+}$ $\mathrm{T}$ cells and NKT cells was significantly higher among the 

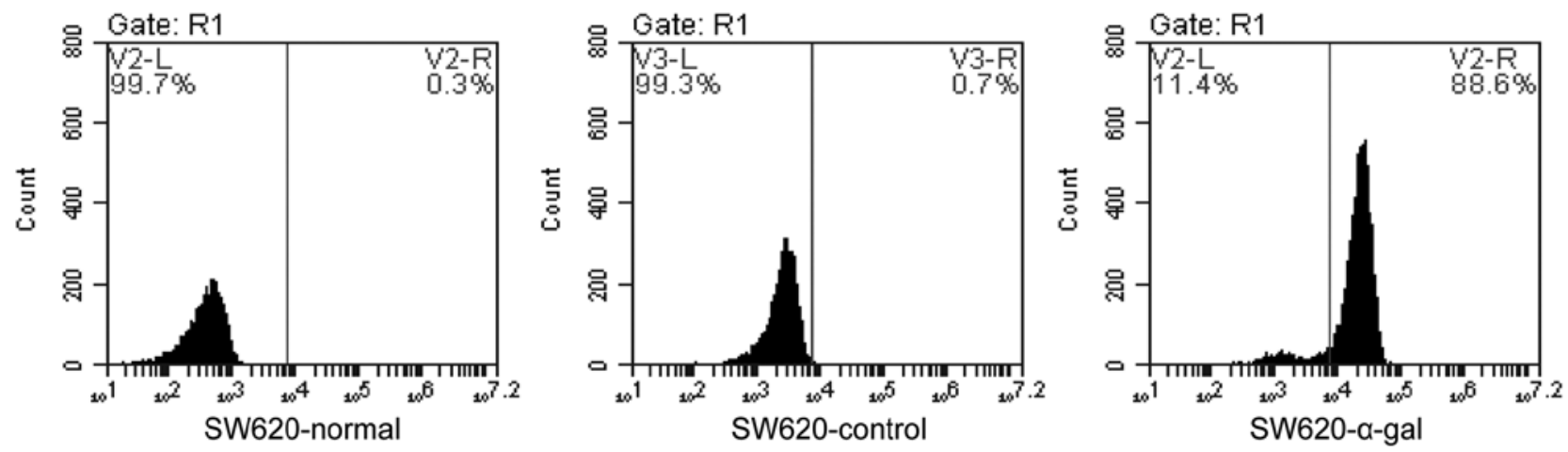

Figure 2. Expression of $\alpha$-gal epitopes on SW620 cells. Colorectal cancer SW620 cells were transfected with recombinant lentivirus vector expressing $\alpha 1,3 \mathrm{Galantosyltransferase}$ gene. The expression of $\alpha$-gal epitopes on SW620-normal, SW620-control and SW620- $\alpha$-gal cells was measured using flow cytometry. In total, $>88 \%$ of SW620- $\alpha$-gal cells expressed $\alpha$-Gal epitopes on the surface of the tumor cells.
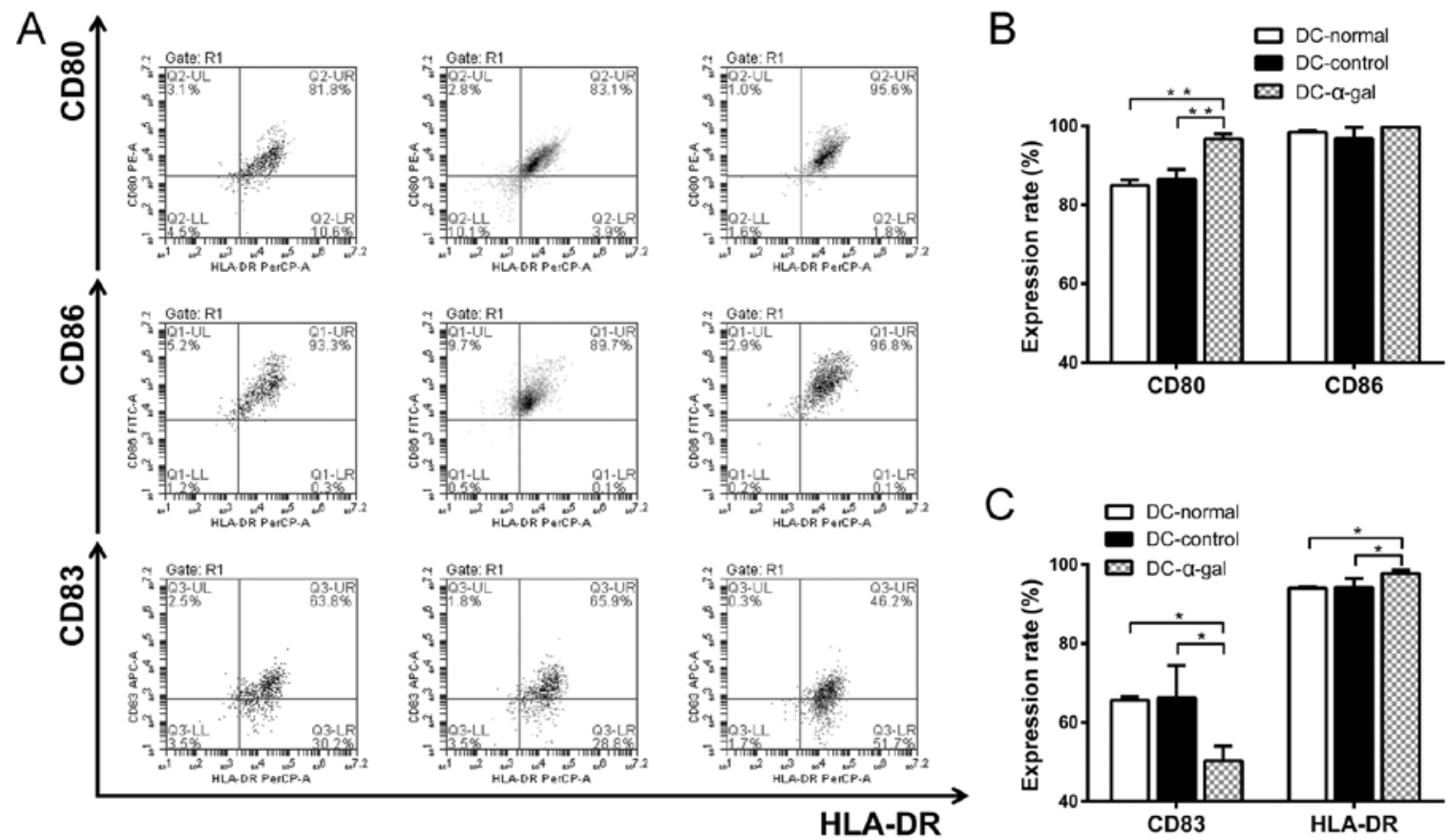

Figure 3. Tumor lysate expressing $\alpha$-gal epitopes promotes CD80 and HLA-DR expression of DCs. On day 5, DCs were cultured with tumor cell lysate. On day 7, mature DCs were harvested. (A) Molecular markers of DCs, including CD80, CD86, CD83 and HLA-DR, were measured using flow cytometry. The results revealed a higher expression of (B) CD80 and (C) HLA-DR in DC- $\alpha$-gal compared with DC-control and DC-normal. ${ }^{*} \mathrm{P}<0.05$, ${ }^{* *} \mathrm{P}<0.01$. HLA, human leukocyte antigen; DC, dendritic cell.

CTLs activated by DC- $\alpha$-gal (CTL- $\alpha$-gal) compared with the CTLs activated by DC-normal (CTL-normal) and DC-control (CTL-control). The frequency of $\mathrm{CD}^{+} \mathrm{CD}^{+} \mathrm{T}$ cells and Tregs was significantly lower among CTL- $\alpha$-gal cells. The cytokine production analyses demonstrated that the level of TNF- $\alpha$ secreted by CTL- $\alpha$-gal cells was significantly higher compared with that secreted by CTL-normal and CTL-control cells, whereas the level of IL-4 secreted by different CTLs was comparable (Fig. 6).

Cytotoxic effect of CTLs on the target cells SW620-normal, SW-620-control and SW620- $\alpha$-gal. The cytotoxic activity against SW620-normal, SW-620-control and SW620- $\alpha$-gal cells was assessed using CTLs induced by different DCs. The effector target ratio was 10:1. As presented in Table I, the strongest killing effect was observed when CTL- $\alpha$-gal cells were applied to kill SW620- $\alpha$-gal cells. At the same effector target ratio, the killing effect of CTL- $\alpha$-gal cells on SW620-normal cells was significantly greater compared with that of CTL-normal and CTL-control cells. Furthermore, when SW620-control was applied as the target cells, the killing effect of CTL-control was significantly greater compared with that of CTL-normal and CTL- $\alpha$-gal cells. These results indicate that more effective tumor-specific CTLs can be induced by DCs pulsed with $\alpha$-gal expressing tumor lysate.

\section{Discussion}

Previous immunotherapy strategies for the treatment of CRC have demonstrated promising results; however, the clinical benefits were limited (22-25). There may be several possible reasons for the insufficient antitumor effect of immune cells. 

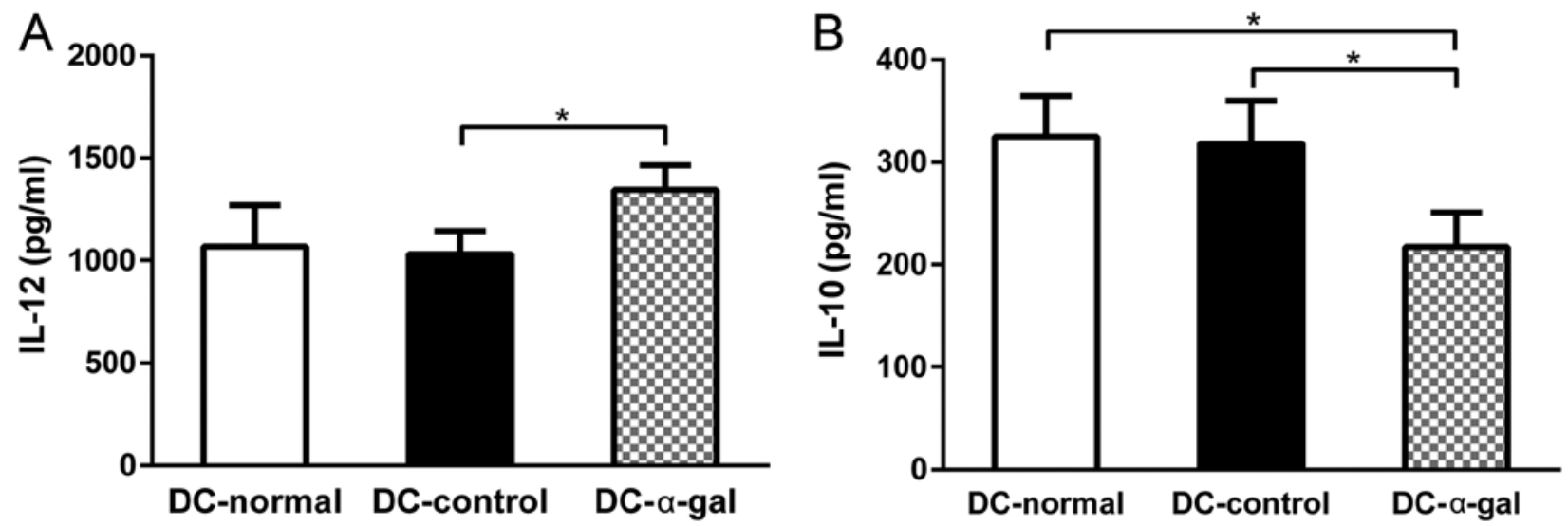

Figure 4. Concentrations of IL-12 and IL-10 in different DC culture supernatants were detected using ELISA. ELISA revealed (A) higher levels of IL-12 and (B) lower levels of IL-10 in DC- $\alpha$-gal culture supernatants compared with DC-control and DC-normal culture supernatants. "P<0.05. IL, interleukin; DC, dendritic cell.

A
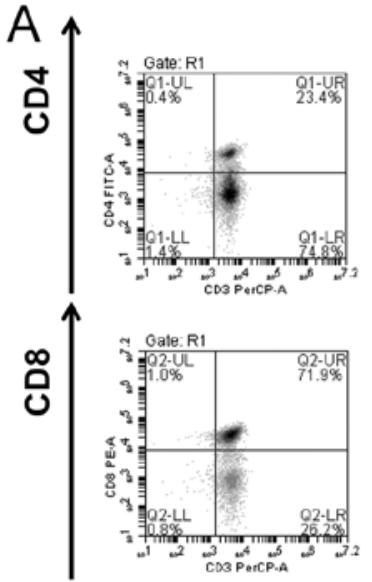

迎

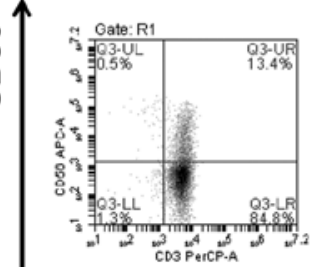

尌
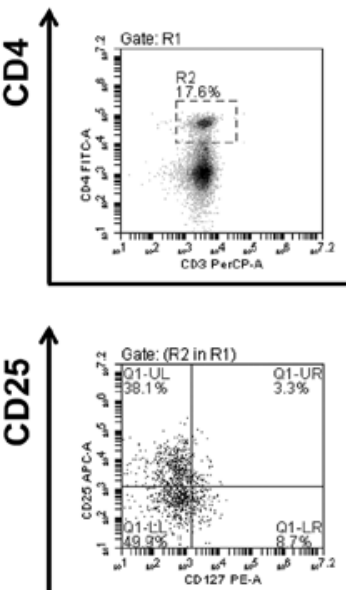
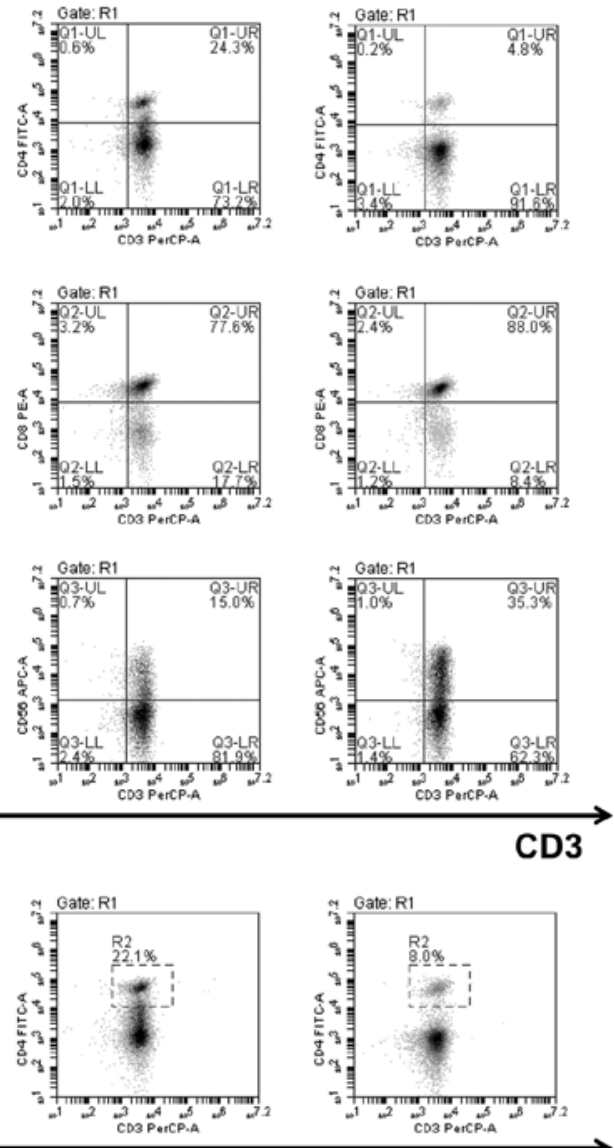

CD3
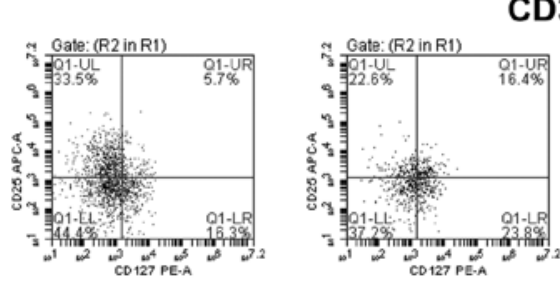

CD127
B

$$
\text { 미 CTL-normal }
$$
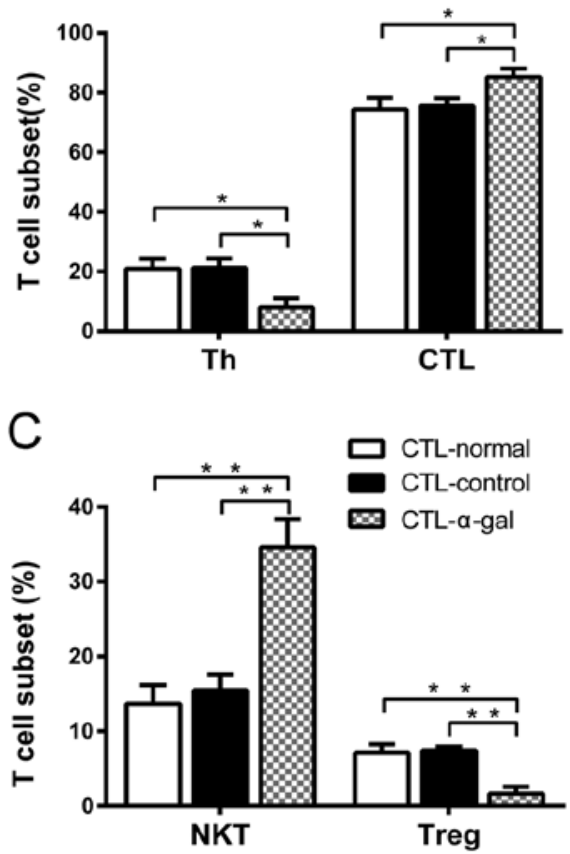

Figure 5. Frequency of $\mathrm{T}$ cell subsets. (A) Percentage of $\mathrm{T}$ cell subsets, including $\mathrm{T}$ helper cells $\left(\mathrm{CD}^{+} \mathrm{CD}^{+}\right)$, $\mathrm{CTLs}\left(\mathrm{CD}^{+} \mathrm{CD}^{+}\right), \mathrm{NKT}$ cells $\left(\mathrm{CD}^{+} \mathrm{CD}^{+} 6^{+}\right)$ and Tregs $\left(\mathrm{CD} 3{ }^{+} \mathrm{CD} 4^{+} \mathrm{CD} 25^{\text {hi }} \mathrm{CD} 127^{10}\right)$, was measured using flow cytometry. The results revealed $(\mathrm{B})$ a lower proportion of $\mathrm{CD} 3{ }^{+} \mathrm{CD} 4^{+} \mathrm{T}$ cells, a higher proportion of $\mathrm{CD}^{+} \mathrm{CD}^{+} \mathrm{CTLs},(\mathrm{C})$ a lower proportion of Tregs and a higher proportion of NKT cells among CTL- $\alpha$-gal cells compared with CTL-control and CTL-normal cells. ${ }^{*} \mathrm{P}<0.05,{ }^{* *} \mathrm{P}<0.01$. CTL, cytotoxic T lymphocyte; NKT, natural killer T cell; Treg, regulatory T cell. 

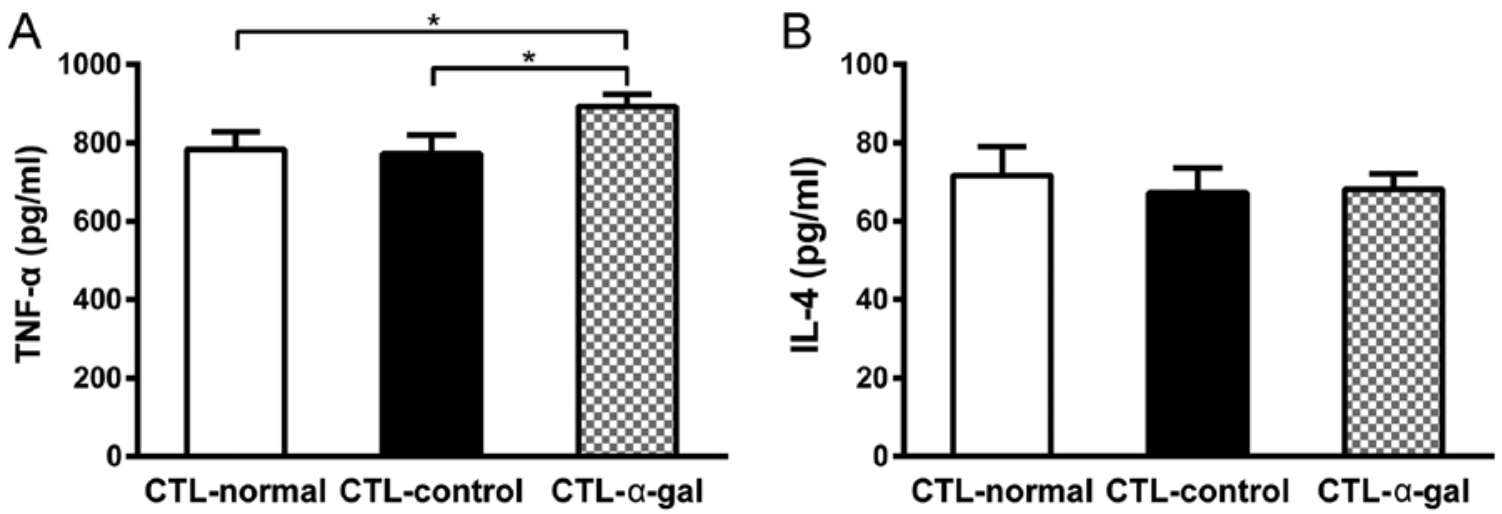

Figure 6. Concentrations of TNF- $\alpha$ and IL-4 in different CTL culture supernatants were detected using ELISA. ELISA demonstrated higher levels of (A) TNF- $\alpha$ in CTL- $\alpha$-gal culture supernatants compared with CTL-control and CTL-normal culture supernatants. (B) No significant difference was observed for the level of IL-4 among the different CTL groups. ${ }^{*} \mathrm{P}<0.05$. TNF- $\alpha$, tumor necrosis factor- $\alpha$; IL-4, interleukin-4; CTL, cytotoxic T lymphocyte.

The first and possibly most important reason is the low immunogenicity of TAAs, which is insufficient to induce tumor-specific immune responses (26). The second reason may be due to the impaired $\mathrm{T}$ cell function of patients with CRC. The tumor-induced suppression of $T$ cell function is recognized as a main factor that contributes to tumor growth and metastasis $(27,28)$. The idea to overcome these problems is to increase the immunogenicity of TAAs and use these highly immunogenic TAAs to pulse DCs, which would subsequently activate tumor-specific CTLs with strong cytotoxicity. The approach described in the present study fulfills the aforementioned requirements. First, $\alpha$-gal epitopes were synthesized on the surface of tumor cells to increase the immunogenicity of TAAs. Subsequently, the adhesive cells from PBMCs were induced to differentiate into DCs, which were pulsed with $\alpha$-gal expressing tumor lysate. Finally, those DCs were co-cultured with naïve $\mathrm{T}$ cells to produce specific CTLs.

In the present study, $\alpha$-gal epitopes were synthesized on the surface of tumor cells to increase tumor antigenicity. Using this approach, $\alpha$-gal expressing tumor lysate could contain foreign antigen $\alpha$-gal and TAAs. The $\alpha$-Gal antibodies bind to $\alpha$-Gal epitopes to form immune complexes and the recognition of immune complexes by activating Fc $\gamma$ receptors expressed on DCs results in the engulfment of the complexes by endocytosis and the maturation of DCs. This maturation includes upregulation of the expression of the co-stimulatory molecule CD80 and the MHC class II molecule HLA-DR (29); therefore, the presentation of TAAs was increased. Induction of a $\mathrm{CD}^{+}$effector $\mathrm{T}$ cell response by $\mathrm{DCs}$ requires the following three signals: MHC class II molecules, including HLA-DR, co-stimulatory molecules, including CD80, and signal pro-inflammatory cytokines, including IL-12 (30). The $\alpha$-Gal epitopes increased CD80 and HLA-DR expression of DCs; therefore, two signals may be more effectively activated and more $\mathrm{CD}^{+}$effector $\mathrm{T}$ cells may be induced. TNF- $\alpha$ was predominantly secreted by $\mathrm{CD} 8^{+} \mathrm{T}$ cells and a higher frequency of $\mathrm{CD}^{+} \mathrm{T}$ cells led to a higher level of TNF- $\alpha$. The results of the present study demonstrated that CTLs activated by DCs pulsed with $\alpha$-gal expressing tumor lysate elicit significant cytotoxic responses against SW620 and SW620- $\alpha$-gal cells, as determined by a cytolytic assay.
There are several possible reasons for this stronger cytotoxicity. The level of TNF- $\alpha$ secreted by CTL- $\alpha$-gal cells was higher compared with that secreted by CTL-normal cells. TNF- $\alpha$ can bind to tumor necrosis factor receptor 1 to directly induce tumor cells apoptosis (31); therefore, a higher level of TNF- $\alpha$ can decrease tumor proliferation significantly. Additionally, the frequency of $\mathrm{CD}^{+} \mathrm{CTLs}$ among the T cells activated by DCs pulsed with $\alpha$-gal expressing tumor lysates was higher compared with that among the $\mathrm{T}$ cells activated by DCs pulsed with normal tumor lysates. $\mathrm{CD}^{+}$CTLs can recognize tumor cells by an interaction between their T-cell receptor and the MHC class I peptide complex on the surface of tumor cells, and can eventually kill target cells by the delivery of toxic granule contents that induce apoptosis of tumor cells to which they attach $(32,33)$. Furthermore, the frequency of Tregs among the $\mathrm{T}$ cells activated by DCs pulsed with $\alpha$-gal expressing tumor lysates was lower compared with that among $\mathrm{T}$ cells activated by DCs pulsed with normal tumor lysate. Tregs are potent immunosuppressive cells that can impair the function of $\mathrm{CD}^{+}$CTLs $(34,35)$. A lower frequency of Tregs indicates a lower immunosuppressive effect, which can contribute to the cytotoxicity of $\mathrm{CD}^{+}$CTLs. It has been reported that IL-12 can paralyze Treg activity and inhibit their proliferation (36). The present study indicated that the level of IL-12 secreted by DCs pulsed with $\alpha$-gal expressing tumor lysate was higher; when T cells are co-cultured with those DCs, IL-12 could inhibit the proliferation of Tregs. This may explain the lower frequency of Tregs among T cells. NKT cells comprise a heterogeneous lymphoid population that exhibit the characteristics of both the innate and adaptive immune system. NKT cells can directly kill tumor cells or indirectly combat cancer via the activation of additional immune cells, thus enhancing tumor immunity (37-39). A higher frequency of NKT cells could be another reason for the significant cytotoxic response observed in the present study.

Although recent studies have reported that $\alpha$-gal epitopes can improve immunogenicity in several types of cancer, the efficacy of $\alpha$-gal epitopes remains controversial $(40,41)$. The application of $\alpha$-gal epitopes to induce a stronger immune response in $\mathrm{CRC}$ required further investigation. The present study provides detailed information for the clinical application 
of $\alpha$-gal epitopes in CRC immunotherapy. However, all the experiments conducted in the present study were in vitro. Although the results are promising, verification of these in future in vivo studies is required. In addition, the signaling mechanisms underlying the enhanced antitumor effect caused by $\alpha$-gal epitopes have not been fully elucidated and require further research.

In summary, the new therapeutic immunotherapy approach evaluated in the present study was demonstrated to significantly increase the cytotoxic responses of CTLs against CRC cells in vitro. The mechanism was further clarified by assessing different $\mathrm{T}$ cell subgroups. An increased level of TNF- $\alpha$, higher frequencies of CD8 ${ }^{+}$CTLs and NKT cells, and a decreased frequency of Tregs may contribute to the enhanced cytotoxicity of the CTLs. Further clinical studies are required to test this approach in patients with CRC.

\section{Acknowledgements}

Not applicable.

\section{Funding}

No funding was received.

\section{Availability of data and materials}

All data generated or analyzed during the present study are included in this published article.

\section{Authors' contributions}

$\mathrm{XD}$ designed the experiments. $\mathrm{XX}$ and $\mathrm{ZZ}$ interpreted the data and wrote the manuscript. $\mathrm{CH}, \mathrm{ZH}$ and $\mathrm{YW}$ performed data analysis. KL and WL performed the cellular and biochemical experiments. KL and WL also critically revised the manuscript. All authors contributed to discussions regarding the results and the manuscript. All authors read and approved the final manuscript.

\section{Ethics approval and consent to participate}

The present study was approved by the Ethics Committees of Chinese People's Liberation Army General Hospital (Beijing, China). All procedures were performed in accordance with the Ethical Standards of the Institutional and/or National Research Committee. Written informed consent was obtained from all volunteers.

\section{Patient consent for publication}

Not applicable.

\section{Competing interests}

The authors declare that they have no competing interests.

\section{References}

1. Adam R and Vinet E: Regional treatment of metastasis: Surgery of colorectal liver metastases. Ann Oncol 15 (Suppl 4): iv103-iv106, 2004
2. Ramos A and Hemann MT: Drugs, bugs, and cancer: Fusobacterium nucleatum promotes chemoresistance in colorectal cancer. Cell 170: 411-413, 2017.

3. Khan K, Wale A, Brown G and Chau I: Colorectal cancer with liver metastases: Neoadjuvant chemotherapy, surgical resection first or palliation alone? World J Gastroenterol 20: 12391-12406, 2014.

4. Castro JE and Kipps TJ: Adoptive cellular therapy for chronic lymphocytic leukemia and B cell malignancies. CARs and more. Best Pract Res Clin Haematol 29: 15-29, 2016.

5. Schubert ML, Hückelhoven A, Hoffmann JM, Schmitt A Wuchter P, Sellner L, Hofmann S, Ho AD, Dreger P and Schmitt M: Chimeric antigen receptor $\mathrm{T}$ cell therapy targeting CD19-positive leukemia andlymphoma in the context of stem cell transplantation. Hum Gene Ther 27: 758-771, 2016.

6. Reissfelder C, Stamova S, Gossmann C, Braun M, Bonertz A, Walliczek U, Grimm M, Rahbari NN, Koch M, Saadati M, et al: Tumor-specific cytotoxic T lymphocyte activity determines colorectal cancer patient prognosis. J Clin Invest 125: 739-751, 2015.

7. Zhu H, Yang X, Li J, Ren Y, Zhang T, Zhang C, Zhang J, Li J and Pang Y: Immune response, safety, and survival and quality of life outcomes for advanced colorectal cancer patients treated with dendritic cell vaccine and cytokine-induced killer cell therapy. Biomed Res Int 2014: 603871, 2014.

8. Chou J, Voong LN, Mortales CL, Towlerton AM, Pollack SM, Chen X, Yee C, Robbins PF and Warren EH: Epigenetic modulation to enable antigen-specific T-cell therapy of colorectal cancer. J Immunother 35: 131-141, 2012.

9. GaoD,LiC, Xie X,ZhaoP,Wei X, Sun W,Liu HC, Alexandrou AT, Jones J, Zhao R and Li JJ: Autologous tumor lysate-pulsed dendritic cell immunotherapy with cytokine-induced killer cells improves survival in gastric and colorectal cancer patients. PLoS One 9: e93886, 2014.

10. Baratin M, Kayibanda M, Ziol M, Romieu R, Briand JP, Guiller JG and Viguier M: Amino acid modifications in the wild type sequence p53 232-240 overcome the poor immunogenicity of this self tumour epitope. J Pept Sci 8: 327-334, 2002.

11. Kalinski P: Dendritic cells in immunotherapy of established cancer: Roles of signals 1, 2, 3 and 4. Curr Opin Investig Drugs 10: 526-535, 2009.

12. Iorgulescu JB, Braun D, Oliveira G, Keskin DB and Wu CJ: Acquired mechanisms of immune escape in cancer following immunotherapy. Genome Med 10: 87, 2018.

13. Galili U: Autologous tumor vaccines processed to express alpha-gal epitopes: A practical approach to immunotherapy in cancer. Cancer Immunol Immunother 53: 935-945, 2004.

14. Galili U, Clark MR, Shohet SB, Buehler J and Macher BA: Evolutionary relationship between the natural anti-Gal antibody and the Gal alpha 1----3Gal epitope in primates. Proc Natl Acad Sci USA 84: 1369-1373, 1987.

15. Galili U: Anti-Gal: An abundant human natural antibody of multiple pathogeneses and clinical benefits. Immunology 140: 1-11, 2013.

16. Abdel-Motal UM, Wigglesworth K and Galili U: Mechanism for increased immunogenicity of vaccines that form in vivo immune complexes with the natural anti-Gal antibody. Vaccine 27: 3072-3082, 2009.

17. Huai G, Qi P, Yang H and Wang Y: Characteristics of $\alpha-G a l$ epitope, anti-Gal antibody, $\alpha 1,3$ galactosyltransferase and its clinical exploitation (Review). Int J Mol Med 37: 11-20, 2016.

18. Galili U: Evolution of alpha 1,3galactosyltransferase and of the alpha-Gal epitope. Subcell Biochem 32: 1-23, 1999.

19. Yao X, Dong Z, Zhang Q, Wang Q and Lai D: Epithelial ovarian cancer stem-like cells expressing $\alpha$-gal epitopes increase the immunogenicity of tumor associated antigens. BMC Cancer 15: $956,2015$.

20. Livak KJ and Schmittgen TD: Analysis of relative gene expression data using real-time quantitative PCR and the 2(-Delta Delta C(T)) method. Methods 25: 402-408, 2001.

21. Yan Y, Li S, Jia T, Du X, Xu Y, Zhao Y, Li L, Liang K, Liang W, Sun H and Li R: Combined therapy with CTL cells and oncolytic adenovirus expressing IL-15-induced enhanced antitumor activity. Tumour Biol 36: 4535-4543, 2015.

22. Carluccio S, Delbue S, Signorini L, Setola E, Bagliani A, Della Valle A, Galli A, Ferrante P and Bregni M: Generation of tumor-specific cytotoxic T-lymphocytes from the peripheral blood of colorectal cancer patients for adoptive T-cell transfer. J Cell Physiol 230: 1457-1465, 2015. 
23. Hunyadi J, András C, Szabó I, Szántó J, Szluha K, Sipka S, Kovács P, Kiss A, Szegedi G, Altorjay I, et al: Autologous dendritic cell based adoptive immunotherapy of patients with colorectal cancer-A phase I-II study. Pathol Oncol Res 20: 357-365, 2014

24. Yoshida Y, Naito M, Yamada T, Aisu N, Daibo K, Mera T, Tanaka T, Naito K, Yasumoto K, Kamigaki T, et al: Adoptive chemoimmunotherapy using activated $\alpha \beta \mathrm{T}$ cells for stage IV colorectal cancer. Anticancer Res 36: 3741-3746, 2016.

25. Yoshida Y, Naito M, Yamada T, Aisu N, Kojima D, Mera T, Tanaka T, Naito K, Yasumoto K, Kamigaki T, et al: Clinical study on the medical value of combination therapy involving adoptive immunotherapy and chemotherapy for stage IV colorectal cancer (COMVI study). Anticancer Res 37: 3941-3946, 2017.

26. Wang GZ, Tang XD, Lü MH, Gao JH, Liang GP, Li N, Li CZ Wu YY, Chen L, Cao YL, et al: Multiple antigenic peptides of human heparanase elicit a much more potent immune response against tumors. Cancer Prev Res (Phila) 4: 1285-1295, 2011.

27. Shimizu H, Ito H, Kimura F, Togawa A, Yoshidome $H$ Ohtsuka M, Kato A, Nukui Y and Miyazaki M: Decreased cell-mediated immune status in colorectal cancer patients with hepatic metastasis. Hepatogastroenterology 52: 1106-1109, 2005.

28. Kwak Y, Koh J, Kim DW, Kang SB, Kim WH and Lee HS Immunoscore encompassing CD3+ and CD8+ T cell densities in distant metastasis is a robust prognostic marker for advanced colorectal cancer. Oncotarget 7: 81778-81790, 2016.

29. Ho NI, Huis In't Veld LGM, Raaijmakers TK and Adema GJ: Adjuvants enhancing cross-presentation by dendritic cells: The key to more effective vaccines? Front Immunol 9: 2874, 2018.

30. Ugur M and Mueller SN: T cell and dendritic cell interactions in lymphoid organs: More than just being in the right place at the right time. Immunol Rev 289: 115-128, 2019.

31. Chu WM: Tumor necrosis factor. Cancer Lett 328: 222-225, 2013.
32. Foged C, Hansen J and Agger EM: License to kill: Formulation requirements for optimal priming of CD8(+) CTL responses with particulate vaccine delivery systems. Eur J Pharm Sci 45: 482-491, 2012

33. Gagnon SJ, Wang Z, Turner R, Damirjian M and Biddison WE: MHC recognition by hapten-specific HLA-A2-restricted CD8+ CTL. J Immunol 171: 2233-2241, 2003.

34. Guzmán-Flores JM and Portales-Pérez DP: Mechanisms of suppression of regulatory T-cells (Treg). Gac Med Mex 149: 630-638, 2013 (In Spanish).

35. Schmidt A, Oberle N and Krammer PH: Molecular mechanisms of treg-mediated T cell suppression. Front Immunol 3: 51, 2012.

36. Tian Y, Yuan C, Ma D, Zhang Y, Liu Y, Zhang W, Hou F and Cui B: IL-21 and IL-12 inhibit differentiation of Treg and TH17 cells and enhance cytotoxicity of peripheral blood mononuclear cells in patients with cervical cancer. Int J Gynecol Cancer 21: 1672-1678, 2011 .

37. Fujii S, Shimizu K, Okamoto Y, Kunii N, Nakayama T, Motohashi S and Taniguchi M: NKT cells as an ideal anti-tumor immunotherapeutic. Front Immunol 4: 409, 2013.

38. Robertson FC, Berzofsky JA and Terabe M: NKT cell networks in the regulation of tumor immunity. Front Immunol 5: 543, 2014.

39. Taniguchi M, Harada M, Dashtsoodol N and Kojo S: Discovery of NKT cells and development of NKT cell-targeted anti-tumor immunotherapy. Proc Jpn Acad Ser B Phys Biol Sci 91: 292-304, 2015.

40. Furukawa K, Tanemura M, Miyoshi E, Eguchi H, Nagano H, Matsunami K, Nagaoka S, Yamada D, Asaoka T, Noda T, et al: A practical approach to pancreatic cancer immunotherapy using resected tumor lysate vaccines processed to express $\alpha$-gal epitopes. PLoS One 12: e 0184901, 2017.

41. Xue D, Liang Y, Duan S, He J, Su J, Zhu J, Hu N, Liu J, Zhao Y and Lu X: Enhanced anti-tumor immunity against breast cancer induced by whole tumor cell vaccines genetically modified expressing $\alpha$-Gal epitopes. Oncol Rep 36: 2843-2851, 2016. 